\title{
An effect of strain rate on energy absorption during tensile testing of paper
}

\author{
W. Szewczyk*, M. Lapczyńska**, J. Piwnik**** \\ *Lodz University of Technology, Institute of Papermaking and Printing, ul. Wólczańska 223, 90-924 Łódź, Poland, \\ E-mail: wlodzimierz.szewczyk@p.lodz.pl \\ **Lodz University of Technology, Institute of Papermaking and Printing, ul. Wólczańska 223, 90-924 Łódź, Poland, \\ E-mail: monika.lapczynska@p.lodz.pl \\ ***Bialystok University of Technology, Mechanical Faculty, ul. Wiejska 44C, 15-351 Białystok, Poland, \\ E-mail: j.piwnik@pb.edu.pl
}

cross $^{\text {ref }}$ http://dx.doi.org/10.5755/j01.mech.22.3.12996

\section{Introduction}

Breaking energy is one of the parameters used for estimation of paper properties. On a stress-strain curve, it illustrates surface area under a curve depicting force changes in elongation function.

In order to make breaking energy independent from a size of sample, tensile energy absorption (TEA) was introduced. It is expressed by the following formula:

$$
T E A=\frac{W_{z}}{s \times l},
$$

where $W_{z}$ is breaking energy, $l$ is initial test span and $s$ is specimen width. In order to make TEA independent from paper grammage, tensile energy absorption index (TEAI) was introduced. It is expressed by the following formula:

$$
T E A I=\frac{T E A}{g},
$$

where $g$ is paper grammage. Due to distribution anisotropy of mechanical properties in paper plane, breaking energy depends on the direction in which the paper is stretched. Measurements are usually made in main directions in paper plane, that is in the machine direction (MD) which coincides with the direction of the web and in the cross direction (CD), which is perpendicular to the machine direction. Measurements of paper breaking energy are a subject of numerous research projects [1-4] however they are usually carried out in standardized conditions, e.g. in accordance with ISO 1924-2: 2008 using a given strain rate. When using, papers can be stretched at different speeds what has a great impact on a value of breaking strength. The literature, however, misses this sort of information. Paper has properties of visco-elastic bodies [5-7] and for this reason the time in which a measurement is carried out affects a relationship between the force and the strain in one direction tensile test. It means that the shape of the stress-strain curve depends on the speed at which paper is stretched. In order to avoid the effect of dynamic loads on the results of paper tensile tests, the tests are carried out in the range of quasi-static speed. In papermaking science, the static tests are the tests made at speed up to $3.3 \times 10^{-4} \mathrm{~m} / \mathrm{s}$. The quasi-static tests are carried out at speed of $0.1 \mathrm{~m} / \mathrm{s}$ [8]. Fig. 1 shows the results of the load-elongation relationship for sack paper (CD) at different tensile speed [9].

In the initial phase of the test, when elastic strains dominate, the stress-strain curves coincide, whereas the curves obtained for higher tensile speed show higher forces at the same strain. As a result, along with decreased tensile speed the value of breaking energy drops. Similar relationships were obtained in this research project (Fig. 2).

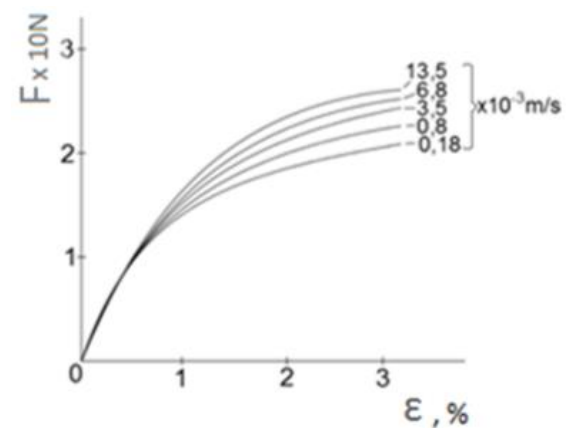

Fig. 1 Load-elongation relationship for sack paper in CD at different tensile speed [9]

Within the range of tensile speed below $100 \mathrm{~mm} / \mathrm{min}$, where the effect of inertia forces can be omitted, the strain at the moment of breaking does not depend from tensile speed. Regardless of tensile speed, paper samples break at similar strain unlike breaking force which changes with variations in tensile speed. In each case described here, variations in tensile speed cause differences in surface area under the stress-strain curve and in the value of breaking energy.

\section{Methods and results}

In order to verify the effect of tensile speed on breaking energy, the tests with papers listed in Table 1 were carried out.

Table 1

Characteristics of papers used in the tests

\begin{tabular}{|c|l|c|c|}
\hline $\begin{array}{c}\text { Designation } \\
\text { of paper }\end{array}$ & Grade of paper & $\begin{array}{c}\text { Grammage, } \\
\mathrm{g} / \mathrm{m}^{2}\end{array}$ & $\begin{array}{c}\text { Thickness, } \\
\mathrm{mm}\end{array}$ \\
\hline P1 & Krafliner & 090 & 0.15 \\
\hline P2 & Fluting & 090 & 0.14 \\
\hline P3 & Printing paper & 090 & 0.14 \\
\hline P4 & Testliner & 125 & 0.22 \\
\hline P5 & Fluting & 135 & 0.21 \\
\hline P6 & Tracing paper & 065 & 0.07 \\
\hline
\end{tabular}


In order to have representative results for different papers, regardless of their fibrous composition and structure, the following grades were used in the tests: papers from secondary fibres (testliner), primary fibres with $10 \%$ of secondary fibres (kraftliner), hardwood primary fibres with $30 \%$ of secondary fibres (fliuting), as well as papers with large dosage of fillers (printing paper) and with high density (trading paper).

For all the papers, breaking energy and tensile energy absorption index in MD and CD were measured after having conditioned them at temperature of $23^{\circ} \mathrm{C}$ and relative humidity of $50 \%$. Conditioning was carried out in the way that moisture equilibrium was obtained in adsorption process. Tensile tests were carried out with $15 \mathrm{~mm}$ wide paper strips. Their initial clamping length was $180 \mathrm{~mm}$. Different tensile speed was used in the tests: $100 \mathrm{~mm} / \mathrm{min}, 10 \mathrm{~mm} / \mathrm{min}$, $1 \mathrm{~mm} / \mathrm{min}, 0.1 \mathrm{~mm} / \mathrm{min}, 0.01 \mathrm{~mm} / \mathrm{min}, 0,001 \mathrm{~mm} / \mathrm{min}$. Tensile test results at different speed are shown in Fig. 2.

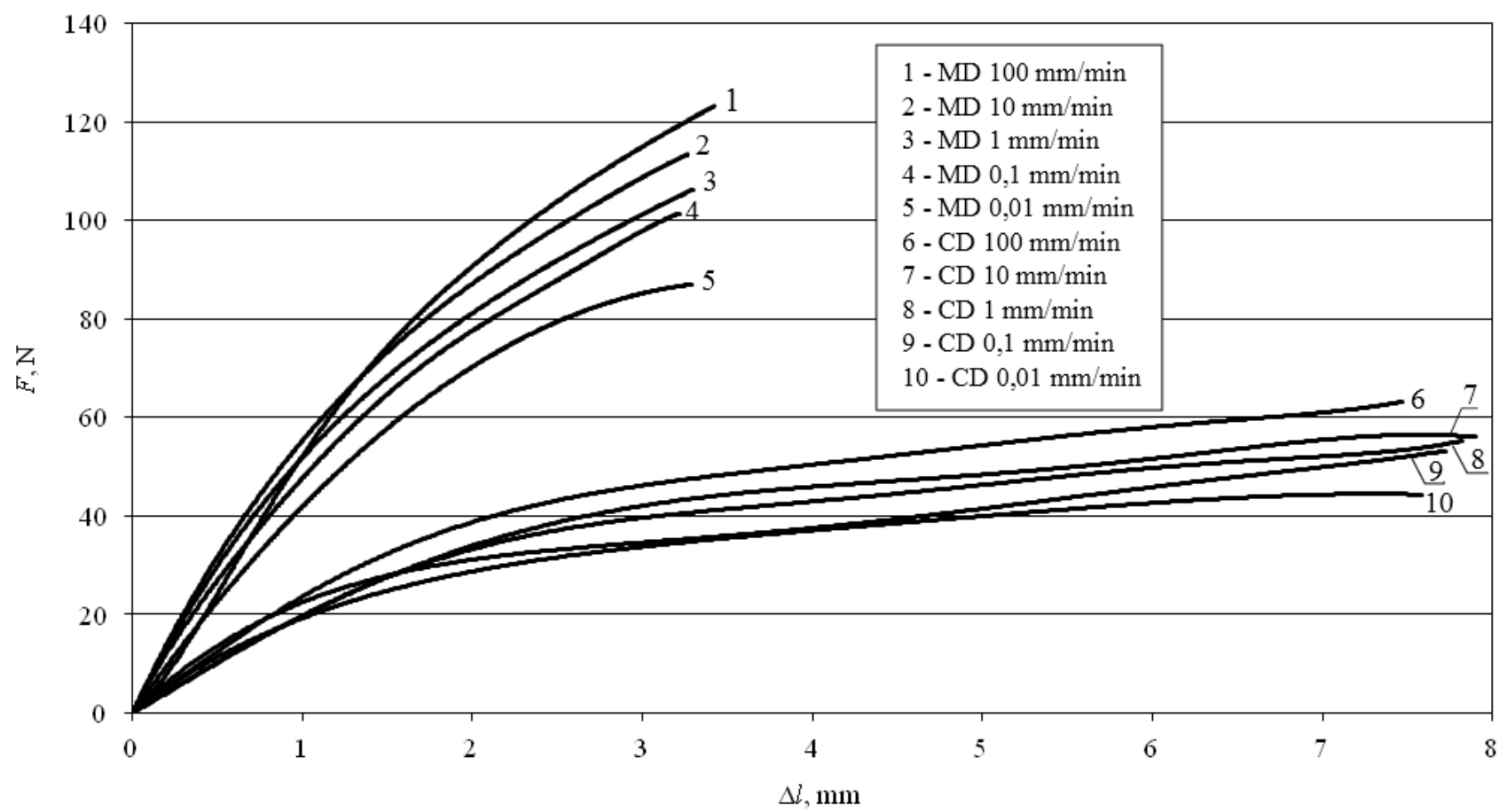

Fig. 2 Tensile test results for paper P1 at different speed

Minor differences in values of breaking strain $\Delta l$ obtained for different tensile speed in static tests are random and they result from heterogeneous fibre structure of paper. It can be concluded then that in the range of used static and quasi-static tensile speed, the strain value at the moment of breaking of a given paper does not change. In case of breaking forces, their values grow clearly with increased tensile speed (Fig. 2).

Breaking energy $W_{z}$ can be determined theoretically from the following formula:

$$
W_{z}=\int_{o}^{\Delta l_{z}} F(\Delta l) d \Delta l
$$

where $F(\Delta l)$ is function depicting relationship between elongation $\Delta l$ and force $F$ in one direction tensile test and $\Delta l_{z}$ is elongation at the moment of breaking.

The calculations for breaking energy can be carried out knowing a function depicting the stress-strain curve $F(\Delta l)$, but for different tensile speed, these relationships are different.

Force $F$ and elongation $\Delta l$ can be presented as dimensionless values $F_{b}, \Delta l_{b}$ expressed by the following relationships:

$$
F_{b}=\frac{F}{F_{z}}
$$

$$
\Delta l_{b}=\frac{\Delta l}{\Delta l_{z}} .
$$

It allows to present all the curves obtained at different tensile speed in a co-ordinate system $\left(\Delta l_{b}, F_{b}\right)$. In further part of the article it is called a relative co-ordinate system, where the curves have the same initial $(0,0)$ and final $(1,1)$ points.

Using the method described in the article, the stress-strain curves can be presented in a relative coordinate system, in which forces and elongation are divided by breaking force and strain at the moment of breaking (Fig. 3).

As Fig. 3 shows, in the relative co-ordinates system, the curves obtained at different tensile speed of the same paper have not only the same initial point $(0,0)$ but also the final one $(1,1)$. They also have similar shape allowing to describe them with one relationship.

As Fig. 3 shows, in the relative co-ordinates system, the curves obtained at different tensile speed of the same paper have not only the same initial point $(0,0)$ but also the final one $(1,1)$. They also have similar shape allowing to describe them with one relationship.

On the basis of the analysis of the measurements results of all the papers tested it was concluded that sufficient mapping accuracy of the stress-strain curve can be obtained using a polynomial of degree 6 . 
CD

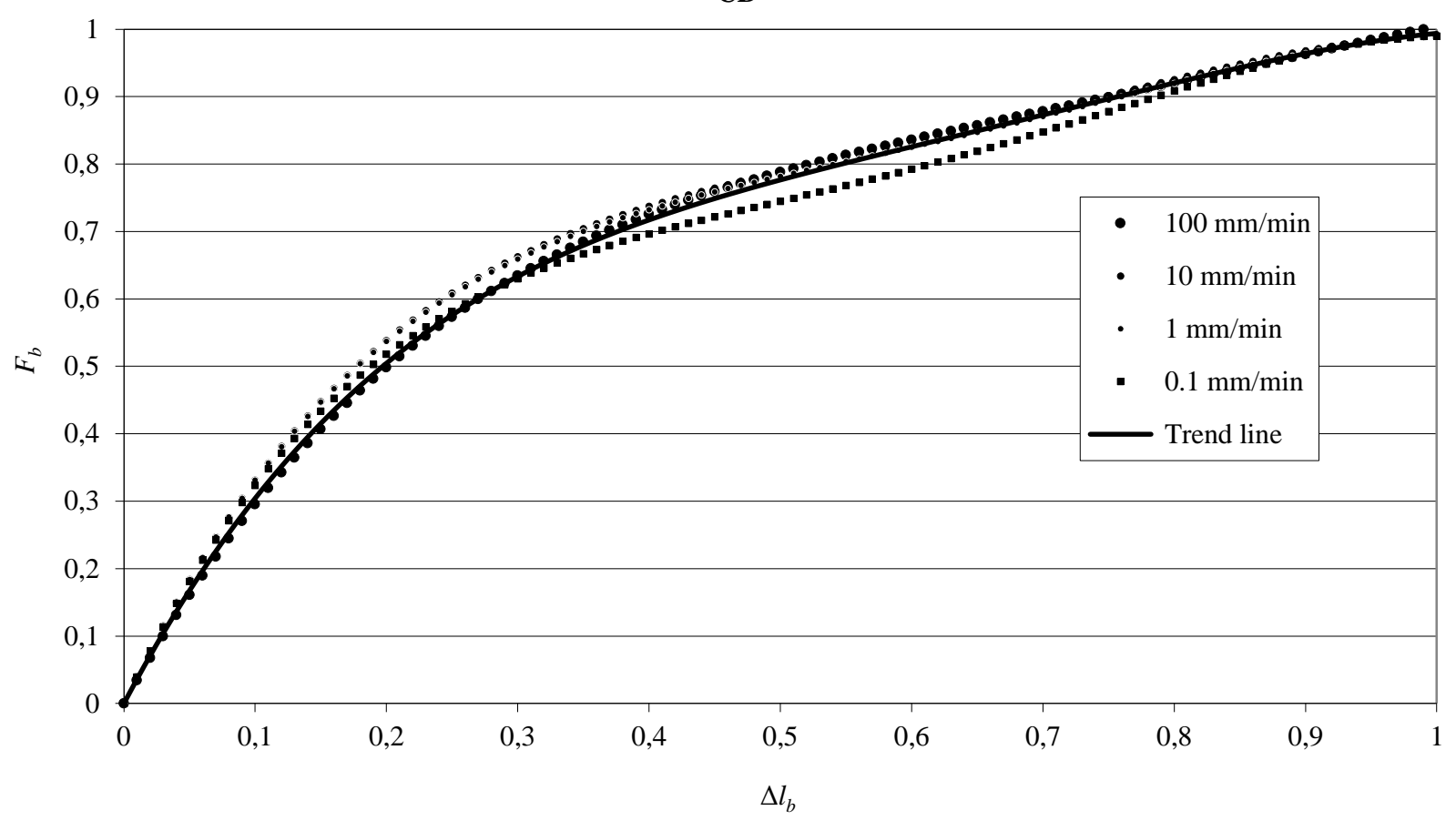

MD

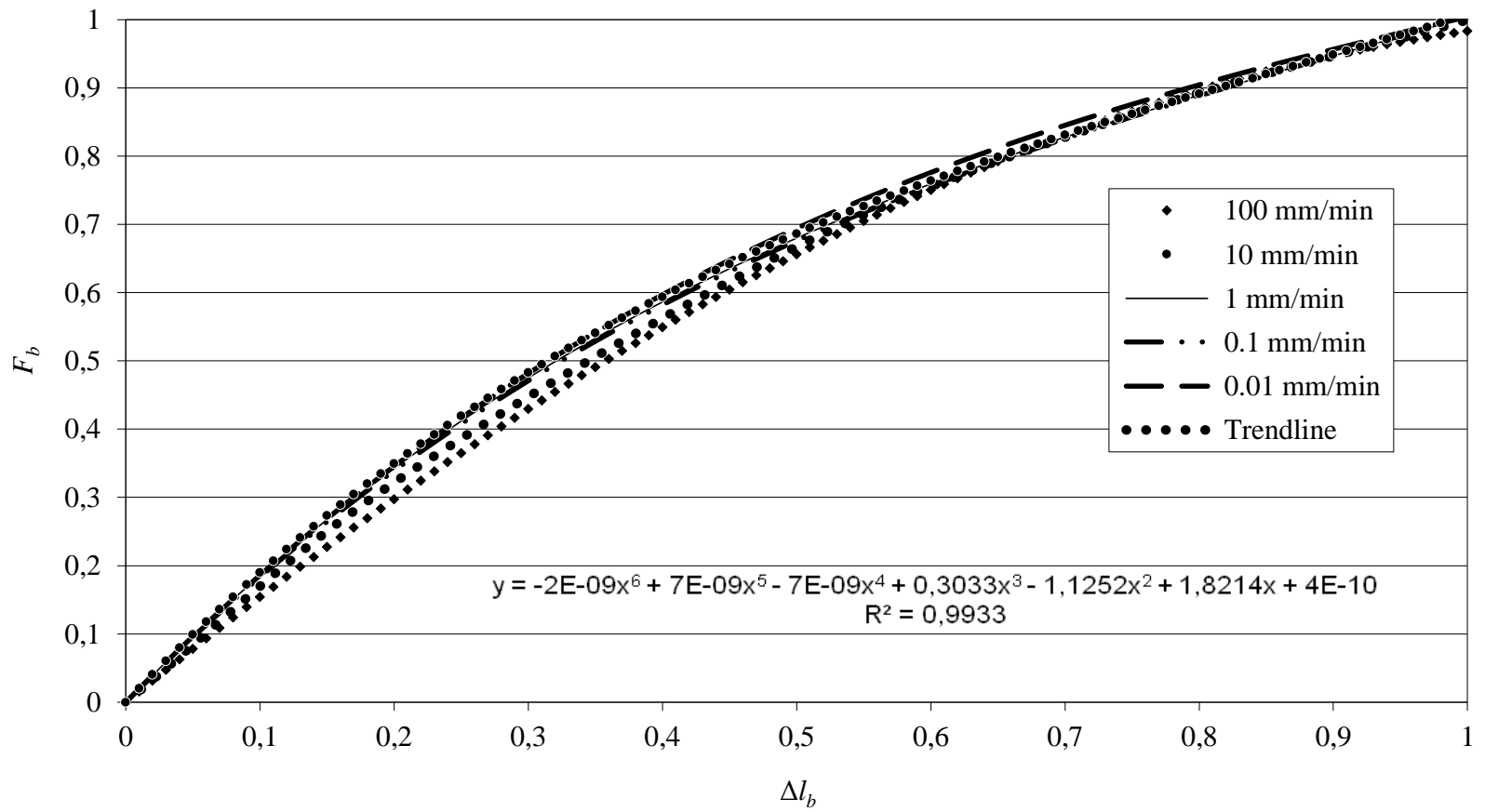

Fig. 3 Stress-strain curves for paper P1 presented in the relative coordinate system

$$
F_{b}=\sum_{i=1}^{6} a_{i} \Delta l_{b}^{i},
$$

where $a_{i}$ is constant determined on the basis of tensile test results.

For any tested paper, coefficient of correlation $R$ between measured values and the values determined by the trend line fits in machine direction in the range of 0.991 and in cross direction in the range up to 0.987 .

Alike for each paper, a common trend line for the stress-strain curve of all the papers tested, and the result obtained for the machine direction is shown in Fig. 4.
Coefficient of correlation $R$ between measured values and the values determined by the trend line was 0.991 in the machine direction and 0.964 in the cross direction.

Using constants $a_{i}$ determined in the relative co-ordinate system and returning to the co-ordinate system of the force and elongation, the following formula is obtained:

$$
F=F_{z} \sum_{i=1}^{6} a_{i}\left(\frac{\Delta l}{\Delta l_{z}}\right)^{i} .
$$


After substituting (7) into (3), the relationship allowing to calculate breaking is obtained:

$$
W_{z}=F_{z} \Delta l_{z} \sum_{i=1}^{6} \frac{a_{i}}{i+1} \text {. }
$$

In order to calculate breaking energy from relationship (8), it is necessary to know the co-ordinates of the breaking point.

For all the papers tested, similar variations of breaking force in the function of tensile speed were obtained. The relationships between these values for the machine and the cross direction are presented in Fig. 5.

Variations of breaking force $F_{z}$ in the function of tensile speed $V_{r}$ can be described by logarithmic relationship:

$$
F_{z}=a \cdot \ln \left(V_{r}\right)+b,
$$

where $a$ and $b$ are constants determined experimentally on the basis of results of breaking tests carried out with different tensile speed.

Knowing values of breaking forces $F_{z 1}$ and $F_{z 2}$ obtained at two different tensile speeds $V_{r 1}$ and $V_{r 2}$ breaking force $F_{z}$ obtained at any tensile speed $V_{r}$ can be calculated from the following relationship:

$$
F_{z}=\frac{F_{z 1}-F_{z 2}}{\ln \left(V_{r 1}\right)-\ln \left(V_{r 2}\right)} \cdot\left[\ln \left(V_{r}\right)-\ln \left(V_{r 1}\right)\right]+F_{z 1} .
$$

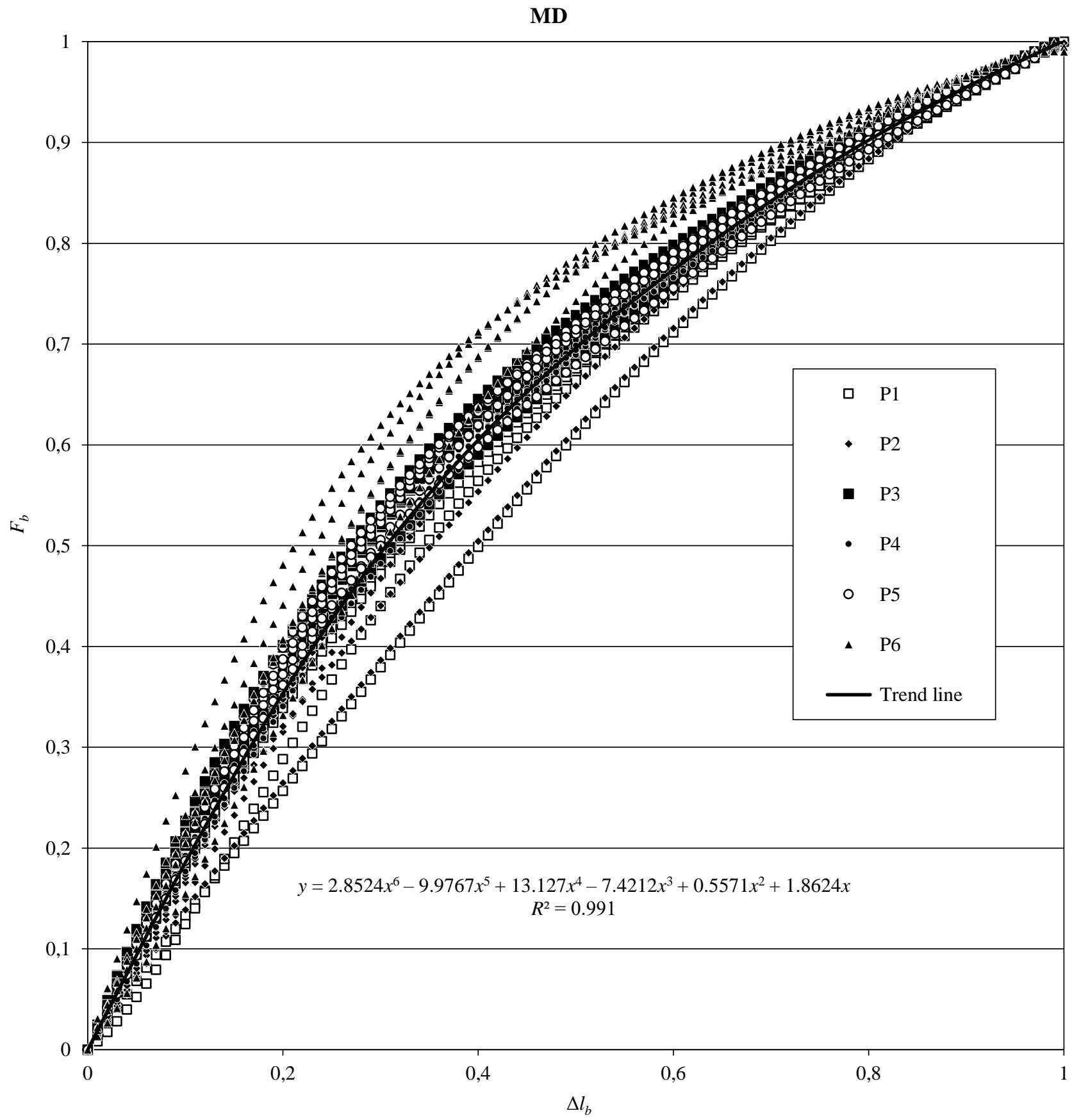

Fig. 4 Stress-strain curves of tested papers, obtained for different tensile speed 
MD

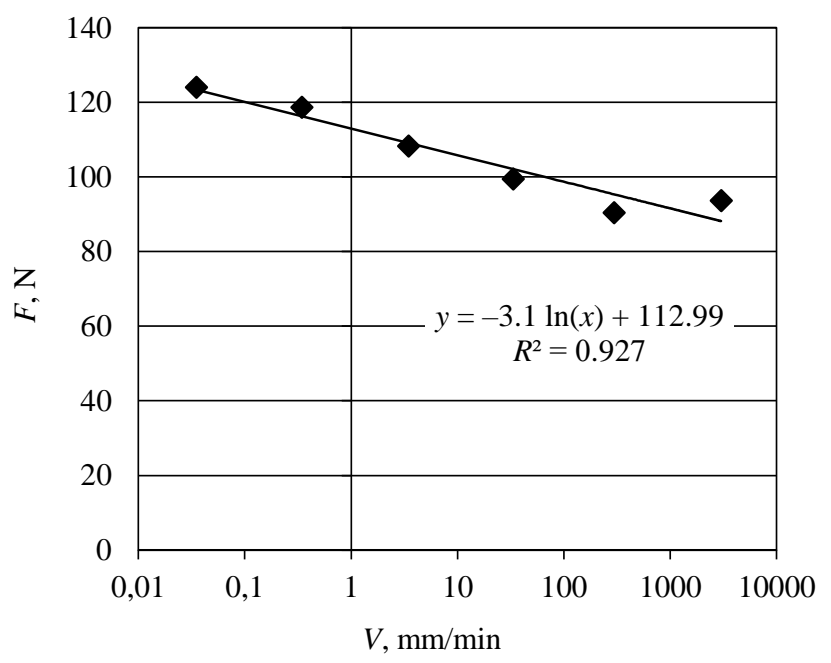

CD

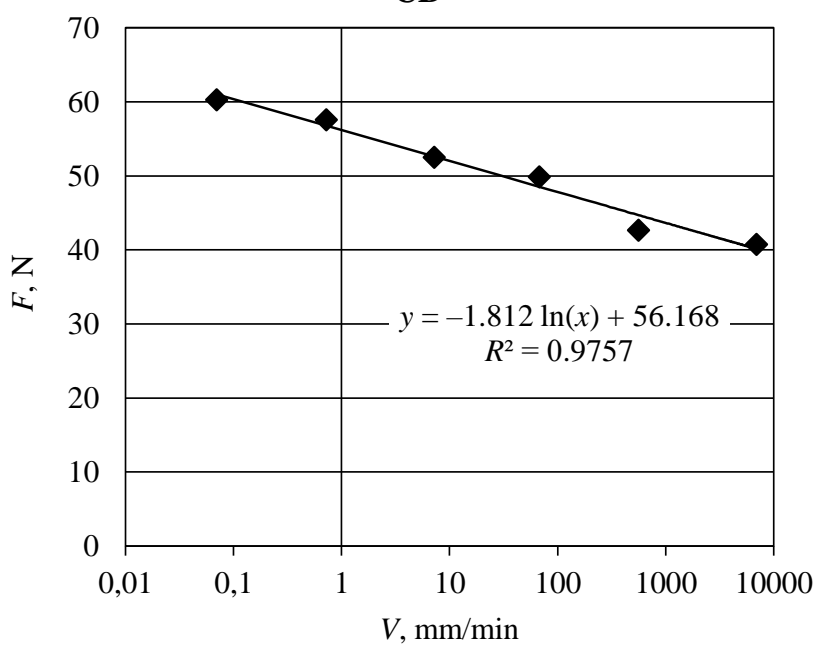

Fig. 5 Variations of breaking force in function of tensile speed shown in logarithmic scale for paper P1

Due to the fact that the strain differences at the moment of breaking for different tensile speed in the static and quasi-static range are random and minor and result from heterogeneity of paper and measurement errors, elongation at the moment of breaking $\Delta l_{z}$ can be described as an average value of strain obtained for different tensile speed. According to the method described in the article, the coordinates of breaking points were determined, breaking energy of tested papers was calculated from relationship (8)

MD

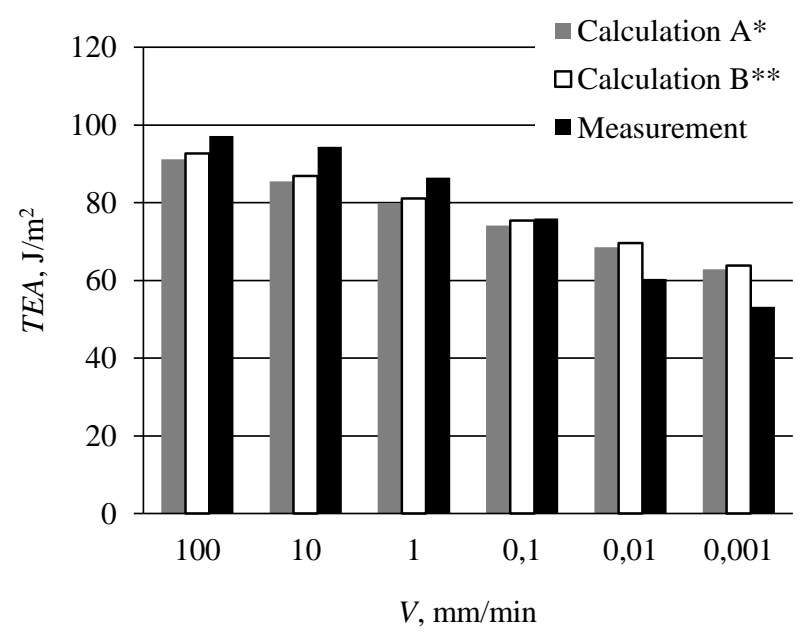

determining constants $a_{i}$ in two ways: from Fig. 5;

- on the basis of tensile tests of all the papers, data

- with the trend line determined on the basis of two tensile tests of a given paper at the speed of $10 \mathrm{~mm} / \mathrm{min}$ and $0.1 \mathrm{~mm} / \mathrm{min}$.

Fig. 6 compare the measurement and calculation results for tensile energy absorption (TEA) of selected papers.

CD

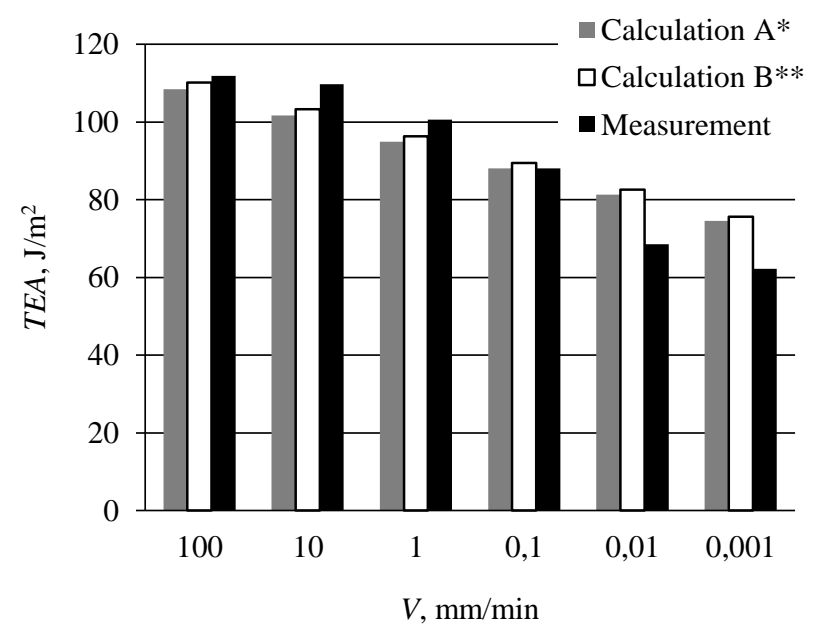

Fig. 6 Tensile energy absorption for paper P1 depending on tensile speed: $* a_{i}$ calculated on the basis of tensile tests of all papers; $* * a_{i}$ calculated with two tensile tests

The tests proved that the suggested calculation method for paper breaking energy gives the results that correspond with the measurement results. The main advantage of the method is a possibility to anticipate breaking energy for a given paper at any speed based on the results of the tensile tests for this paper for two different speeds.

\section{Conclusions}

In case of the static one direction tensile tests, the energy absorbed during the tensile stress of papers gets smaller with decrease of tensile speed. Comparison of the measurement and calculation results proves that the proposed method for theoretical calculation of breaking energy reflects its variations caused by changes in tensile speed of papers and it can be used in the speed range in which an effect of inertia forces on measurement results can be omitted.

In case of the papers of similar structure (e.g. packaging grades), the use of constants $a_{i}$, describing the shape of the stress-strain curves, determined for different papers than the tested ones does not cause a significant calculation 
error. The use of these coefficients for calculation of paper with different structure can increase the calculation error and in such cases better results are achieved by determination of constants $a_{i}$, on the basis of two tensile tests of tested paper.

\section{References}

1. Gigac, J.; Fiserova, M. 2010. Effect of velocity gradient on papermaking properties, Cellulose Chem. Technol. 44(9): 389-394.

2. Potůček, F.; Milichovský, M. 2013. Effect on adding secondary fibers to craft pulp on strength properties an air resistance, Cellulose Chem. Technol. 47(5-6): 455-460.

3. Gonera, H.; Dąbrowski, J. 2007. Termodynamiczne ujęcie procesu starzenia się papieru Część I. Badania zależności wskaźnika pochłaniania energii przy zrywaniu papieru od parametrów jego sztucznego starzenia, Przegl. Papiern. 63(12): 719-727.

4. Houssine, S.; Zhou, V.; Berglund, L.A. 2013. Nanofibrillated cellulose for enhancement of strength in highdensity paper structures, Nordic Pulp \& Paper Research Journal 28(2): 182-189.

http://dx.doi.org/10.3183/NPPRJ-2013-28-02-p182-189

5. Rance, H.F. 1956. The formulation of methods and objectives appropriate to the rheological study of paper, Tappi 39(2): 104-115.

6. Stera, S. 1981. Wpływ procesu wykończania papieru na użytkowe oraz strukturalno-reologiczne własności papieru workowego. Dissertation, Łódź: Politechnika Łódzka, 1981 (in Polish).

7. Gullichsen, J.; Paulapuro, H. (editors.) 1998. Pa- permaking science and technology, Part 16, Paper Physics, Helsinki : Fapet Oy, 1998, pp. 261-268.

8. Göttsching, L. 1970, 1971. Das Festigkeitsverhalten von Papier unter statischer und dynamischer Beanspruchung, Part 3, Paperi ja Puu 52(11): 781-794; Part 4, Paperi ja Puu 53(1): 27-36.

9. Andersson, O.; Sjöberg, L. 1953. Tensile studies of paper at different rates of elongation, Svensk Paperst. 56(16): 615-624.

W. Szewczyk, M. Łapczyńska, J. Piwnik

\section{AN EFFECT OF STRAIN RATE ON ENERGY ABSORPTION DURING TENSILE TESTING OF PAPER}

S u m m a r y

The article analyses an effect of paper strain rate on energy absorbed during tensile testing. The tests were carried out in the range where the effect of inertia forces could be omitted. A new calculation method is proposed to predict variations in breaking energy caused by changes in strain rate. The method was verified by laboratory tests and calculation results and its practical usefulness was confirmed.

Keywords: breaking energy, paper, tensile speed, breaking strength, tensile strength.

Received August 28, 2015

Accepted May 11, 2016 